\title{
The Consequences of Queueing: Crowding, Situational Features and Aggression in Entertainment Precincts
}

\author{
Michael Townsley ${ }^{1}$ and Robert Grimshaw
}

\author{
1: School of Criminology and Criminal Justice, Griffith University \\ m.townsley@griffith.edu.au
}

\section{Abstract}

Alcohol-related violence has long been regarded a serious social problem in Australia. Extensive research has been conducted analysing the relationship between alcohol, crowding and aggression inside licensed premises, consistently finding that situational and social factors play significant roles. However, there is been a dearth of empirical research into these relationships in the public space outside licensed premises and around transport nodes. This study provides such an analysis. A systematic observational measurement was employed on six street segments in the Valley Entertainment Precinct, Brisbane, Queensland that recorded aspects of the physical and social environment, levels of intoxication, street population, queueing practices, crowding and aggression. Over 96 hours of observation, 42 acts of high-level and 94 acts of low-level aggression were witnessed, a far higher rate than previous studies. Relationships between levels of crowding and aggression were observed, even after controlling for major correlates. The results of the study strengthen arguments about the need to consider crowding and queue management issues as well as the design of public spaces in entertainment precincts to reduce aggression.

Keywords: alcohol, aggression, queues, place management, Night-Time Economy

Acknowledgements: We wish to thank Professors Ross Homel and Kathryn Graham for their invaluable advice and access to research materials. We'd also like to acknowledge the advice given by officers from the Brisbane City Council, Queensland Police Service and Valley Liquor Accord on various elements of the research design. 


\begin{abstract}
Alcohol-related violence has long been regarded a serious social problem.

Extensive research has been conducted analysing the relationship between alcohol, crowding and aggression inside licensed premises, consistently finding that situational and social factors play significant roles. However, there has been a dearth of empirical research into these relationships in the public space outside licensed premises and around transport nodes. This study provides such an analysis. A systematic observational measurement was employed on six street segments in the Valley Entertainment Precinct, Brisbane, Queensland that recorded aspects of the physical and social environment, levels of intoxication, street population, queueing practices, crowding and aggression. Over 96 hours of observation, 42 acts of high-level and 94 acts of low-level aggression were witnessed, a far higher rate than previous studies. Relationships between levels of crowding and aggression were observed, even after controlling for major correlates. The results of the study strengthen arguments about the need to consider crowding and queue management issues as well as the design of public spaces in entertainment precincts to reduce aggression.
\end{abstract}

Keywords: alcohol, aggression, queues, place management, Night-Time Economy Acknowledgements: We wish to thank Professors Ross Homel and Kathryn Graham for their invaluable advice and access to research materials. We'd also like to acknowledge the advice given by officers from the Brisbane City Council, Queensland Police Service and Valley Liquor Accord on various elements of the research design. 


\section{Introduction}

Alcohol and the harms associated with excessive consumption is a serious issue on an international national and local scale. Consumption of alcohol in the EU is two and a half times the global average, with the largest proportion of alcohol related health issues and premature deaths in the world (Rehm et al, 2009). The tangible social cost of alcohol to the EU has been estimated at $€ 125$ billion annually, much of this borne by individuals other than the drinker (WHO, 2009). Within Australia the financial costs in 2004/05 were estimated to be AUD\$2billion for alcohol-related deaths and injuries, and AUD\$1.7billion alcohol-related crime (Collins \& Lapsey, 2008). Experience of alcohol-related violence is relatively common in Australia, with a quarter of respondents to a recent national Australian survey reporting being a victim of alcohol-related verbal abuse (Morgan and McAtamney, 2009).

These trends in alcohol-related harms and cost have taken place against a backdrop of market deregulation (Hadfield, 2006; Hobbs et al., 2003; Stockwell and Chikritzhs, 2009). In Australia, reforms largely associated with the National Competition Policy (NCP) have supported the liberalisation of the liquor industry (Livingston, 2008; National Competition Council, 2004). In Queensland, the introduction of Special Entertainment Precincts, place-based entities created by amendments to planning, noise and liquor licensing legislation (Brisbane City Council, 2010), are further changes that Burke and Schmidt (2009) argue place business interests of licensees before the needs of local residents.

Alcohol-related violence has been the focus of much public, media and political attention in recent years (Morgan and McAtamney, 2009; Laslett et al., 2010). In 
2009 the Queensland Government initiated a parliamentary inquiry into alcoholrelated violence; the final report comprised no less than 68 recommendations regarding the direction of future research, trading hours, transport, enforcement and penalties, education and cultural change and the role of parents (Law, Justice and Safety Committee, 2010).

While the link between aggression and alcohol consumption has considerable empirical support, the relationship is far from deterministic. Most people consume alcohol without becoming aggressive or victimised (Plant et al., 2002). Instead, it is the interplay of the pharmacological effects of alcohol on behavioural and cognitive functioning, characteristics of individual drinkers, the drinking environment and cultural expectations of drinking that contribute to the prevalence and extent of aggression (Morgan and McAtamney, 2009). Prevention efforts have concentrated on situational approaches, including responsible serving practices (Graham, 2000a; Stockwell, 2001), effective place management (Graham et al., 2004), police enforcement (Jeffs and Saunders, 1983; Wiggers et al., 2004; Wiggers, 2007), restricting trading hours (Douglas, 1998; Kypri et al., 2011; Stockwell and Chikritzhs, 2009; Voas et al., 2002, 2006) and price controls (Chikritzhs et al., 2009; Österberg, 2004; Wagenaar et al., 2009).

Much of what is known about aggression and violence in licensed venues comes from observational studies (the Safer Bars program was originally an observational study, plus interviews, then developed into a training and risk assessment package for licensees, see Graham et al. (2004) for details). The vast majority of such studies have focused on aggression inside licensed premises, yet 
analysis of crime statistics involving alcohol-related violence (Briscoe and Donnelly, 2001; Fitzgerald et al., 2010; Jochelson, 1997) suggest that a large portion of violence occurs in the public-space outside. In particular, the immediate area around licensed premises and queues for taxis and buses are suggested to be "hotspots" for alcohol-related violence (Cozens and Grieve, 2009; Graham and Hadfield, 2006; Homel, 2008; Wikstrom, 1995). The relationship between crowding and aggression has been suggested in case studies of entertainment precincts (Cozens and Grieve, 2009) and demonstrated using computer simulation models (Moore et al., 2008), but to our knowledge has not been explicitly studied in a systematic manner.

This study set out to measure attributes of the physical and social environment, queueing, crowding and aggression outside licensed venues using an observational methodology. As Homel and Clark (1994, p. 9) state "it is clear that direct observation, supplemented by surveys of staff or patrons, is the best way of studying violence in the natural setting of licensed premises" yet studies focussing explicitly on places immediately outside venues do not appear in the literature. This study aims to contribute to understanding of the ecology of street violence around drinking establishments, an area Graham and Homel (2008, pp. 188-194) believe is in dire need of elaboration to assist in theory and intervention development.

\section{Literature Review}

The theoretical framework underpinning this study is environmental criminology, 
a triumvirate of theories-rational choice theory (Cornish and Clarke, 1986, 2008), routine activity theory (Cohen and Felson, 1979) and crime pattern theory (Brantingham and Brantingham, 2008)-focusing on the immediate, proximate factors that allow the commission of crimes. Two concepts in particular play a central role in understanding violence in licensed premises: crime precipitators and place management.

Richard Wortley $(1997 ; 1998 ; 2001 ; 2008)$ has persuasively argued that proximate factors may invoke criminal behaviour that otherwise would not occur. Situational elements acting in such a way are crime precipitators, of which there are four types. Prompts are stimuli that generate a response, often operating subconsciously (e.g. scantily dressed bar staff may heighten sexual desire). Pressures are social forces that compel behaviour inconsistent with privately held views (e.g. peer pressure to keep up “drink for drink”). Permissions are norm violations that signal certain acts are condoned (e.g. patrons dancing on tables unchallenged provides tacit permission to others). Finally, stressful and frustrating situational elements may provoke negative emotional arousal (e.g. being jostled or pushed navigating through a crowded nightclub environment). Thus, precipitators are factors of the immediate environment that increase individuals' readiness to offend.

John Eck (1994) introduced the concept of place managers, actors who are responsible for regulating legitimate entry and routine behaviours in a specified location, as an enhancement to routine activities theory. Place managers, along with handlers and guardians, control the necessary elements of a crime event: a 
motivated offender, a suitable target and a place where they converge. Place managers in entertainment precincts include door staff, bar staff, licensees, taxi queue stewards, bus and train drivers, conductors and associated staff. Madensen and Eck (2008) demonstrate that management practices and decisions explain crime rates in bars to a greater extent than neighbourhood and patron characteristics.

\section{Environmental factors influencing aggression in licensed premises}

Graham and Homel (2008) synthesised the findings of 11 observational studies of violence in licensed premises to establish key attributes of patrons, the physical environment, the social environment, staff and management practices associated violence and aggression (with respect to risk, frequency or severity). As these studies were conducted over a period of 25 years in Canada, the United States, the United Kingdom and Australia the main limitation in substantiating the generalisability of relationships is the confounding influence of local contexts. Nevertheless, certain attributes demonstrated surprisingly consistent roles in facilitating aggression across studies ${ }^{\mathrm{i}}$.

The most consistent factors related to aggression and the physical environment were the cleanliness of venues, smokiness, poor ventilation and ambient temperature. Graham and Homel (2008) suggest cleanliness is a proxy for management style and serves as a form of expectation setting for patrons. The other attributes of the physical environment are almost certainly acting as precipitators of crime that, in the right circumstance, may provoke patrons to 
behave aggressively.

Levels of crowding, patron movement and noise have been associated with higher levels of aggression. Crowding and patron movement are a type of precipitator, whereby bottlenecks and cross-flows of pedestrians result in unintended bumping, brushing past and shoving. Crowded and congested environments produce stress as competition for resources (space or bar service) increases and leads to aggression.

The most germane study in the extant literature on crowding in barroom environments was conducted by Macintyre and Homel (1997). They observed striking differences in rates of violence across six premises, homogeneous with respect to size of venue, patron density and target demographic. In aggregate, levels of crowding increased with patron density, but the magnitude of this increase was much greater in certain venues. The important finding was that crowded venues hosted more violence, not necessarily those most populated. Using the internal design of the clubs as a guide, they found the number of pedestrian vectors (e.g. bar to dance floor, toilet to bar) that crossed was a strong predictor of crowding. Macintyre and Homel (1997) concluded that good floorplan design would minimise the potential for crowding and congestion and therefore result in less violence.

The social environment has the most consistent and strongest relationships in determining aggression in observational studies. Levels of intoxication, levels of permissiveness, rowdiness and swearing and levels of sexual competition were 
positively correlated in all studies (Graham and Homel, 2008). Of these, permissiveness/rowdiness/swearing had the largest effect size of all variables, predicting both the amount and severity of aggression observed. The reason these factors are so powerful is they are directly linked to all four forms of situational precipitators, that is the social environment of licensed venues comprise situations that "present cues which prompt the individual to perform criminal behavior, they can exert social pressure on an individual to offend, they can induce disinhibition and permit potential offenders to commit normally proscribed illegal acts, and they can produce emotional arousal which provokes a criminal response" (Wortley, 1998, p. 175, emphasis in original).

While a consistent association between intoxication and aggression was observed in observational studies, factors facilitating alcohol consumption (e.g. drinks specials, round buying) also result in increased aggression. Graham and Homel (2008) stress that this finding illustrates the importance of the person-situation interaction; individual factors as well as the nature of the drinking environment are instrumental in setting the scene for violence.

\section{Aggression outside licensed premises}

While the focus of most observational studies has been on interactions inside premises, some limited information about what happens outside premises is available. For instance, Canadian studies (Graham et al., 2000; Graham and Wells, 2001; Graham et al., 2006) indicate that queues for entry are a frequent location 
for aggression. In Toronto, the number of patrons loitering outside a venue after closing is positively correlated with the amount and severity of aggression (Graham et al., 2006). In an observational study of violence in Glasgow City centre pubs, Forsyth et al. (2005) reported more acts of violence outside pubs after closing time than inside ${ }^{\mathrm{ii}}$.

Studies examining the prevalence and incidence of violence outside licensed premises have predominantly used secondary data analysis of recorded crime data, calls for service data, ambulance data and hospital data (Block and Block, 1995; Burrell and Erol, 2006; Donkin and Birks, 2007; Nelson et al., 2001; Newton et al., 2007; Moore et al., 2011; Murray, 2011; Pointing et al., 2011; Poynton et al., 2005; Roncek and Maier, 1991), metrics which are subject to well known reporting and recording filters. Surprisingly few analyses have been carried out that exploit multiple datasets, although Lesjak et al. (2008) (police and heath) and Murray (2011) (police, ambulance and hospital) are recent exceptions. While secondary data analysis provides good information about aggregate trends, dynamics of social problems occurring at the micro-level are difficult to uncover, yet are vital for informing interventions.

Graham and Homel (2008) list two key ways in which violence occurring outside licensed premises is linked to individual venues: (a) venue management practices (unfair or confrontational entry policies and disproportionately aggressive exit/ejection practices) and (b) the extent of queueing and congregation in the public space (clashes between groups, pedestrian movement between venues and crowds gathering around conflicts). 


\section{Research questions}

Alcohol-related violence is an important, topical social problem. The extant prevention literature has shown that controlling a range of situational factors helps reduce violence and aggression inside licensed premises. However, the formation of entertainment precincts in cities and major towns (driven by the forces of market deregulation and spatial clustering of outlets) suggest that focusing on individual venues may no longer be sufficient. The problem of alcohol-related violence in public spaces is no longer one of managing "bad bars" but of managing places (Hadfield and Measham, 2011). Much scholarly research now focuses on whole entertainment precincts or the liquor industry rather than individual venues (Hadfield, 2006; Hobbs et al., 2003).

Given the changes to the nighttime economy, widespread public concern about levels of alcohol- related violence, and the lack of empirical studies looking at violence outside nightclubs, it seems timely to explore the nature of aggression in the public space and whether situational factors play a similar role outside as they do inside. This study aims to answer the following questions:

1. What causes crowding in the public space in entertainment precincts? Is crowding simply a result of patron density, or are certain locations prone to excessive crowding? What makes these places different from locations without crowding? 
2. Does excessive crowding directly lead to increased aggression? If so, is this over and above the effect of major situational correlates, such as level of intoxication, permissiveness, etc?

\section{Methodology}

\section{Study region}

Fortitude Valley is Brisbane's premier late-night music and entertainment hub, attracting up to 50,000 patrons on a busy Saturday night, with a residential population of only 5,000 (Office of Liquor and Gaming Regulation, 2011), and in 2006 became Australia's first Special Entertainment Precinct (Brisbane City Council, 2010). It is dissected by two main arterial roads that provide the key routes into, out of and through Fortitude Valley and the adjacent Brisbane CBD. There are several popular large, late-night trading licensed venues and a mix of smaller licensed venues. 75 licensed venues, numerous restaurants as well as a late-night train station, taxi ranks and bus stops are housed in a 1.5 square kilometer area. It is one of the three Drink Safe Precinct pilot sites, a key response by the Queensland Government to the parliamentary inquiry into alcohol-related violence (Queensland Government, 2010). 


\section{Observation sites}

As the focus of this study was the public space outside licensed premises, the unit of analysis was "block faces". This allows a clearly defined area to be observed, rather than "Outside Nightclub X". It also allowed observers to capture the interactions between the different queues formed within a block face and the pedestrians passing. The selection of sites for this study involved discussions with Brisbane City Council, Queensland Police Service and the Valley Liquor Accord to nominate a list of "hotspots" for violence and large crowds. A short list of nine sites was established that was reduced to six for reasons of observer safety and inadequate observation capacity. An additional criterion for inclusion was to capture a mix of land use, venue size and number. Table 1 lists the six observational sites.

<insert Table 1 about here>

Sites One to Four all incorporate at least two or more licensed premises. Site One also features the main late-night bus stop. Sites Five and Six contain primarily transport queues, with the only other queue generator at either site being an ATM in Site Six. Queues for entry into the railway station are formed in Site Five due to the location of the station within a private shopping centre. The shopping centre management lock the entry doors into the centre after the last train of the night and open the doors ten minutes before the first train arrives in the early hours of the next morning, forcing people to queue on the footpath. Figure 1 displays the sites in the context of the Fortitude Valley suburb. The shaded overlays represent 
approximations of the observed "block faces" with the slight offsetting indicating the side of the street that was under observation.

<insert Figure 1 about here>

\section{Observers}

14 Griffith University undergraduate students were recruited and trained to be observers. The response rate for female students was much greater than males (11 vs 3), resulting in an inability to form male/female pairs consistently across all sites every night. Mixed gender pairs have been utilised in previous studies as they are less conspicuous and safer (Forsyth et al., 2005; Forsyth, 2006; Graham et al., 2006; Macintyre and Homel, 1997). Six teams of pairs were used each night (with two reserves used in case of illness of other absence). Observers were rostered equally across time and duration, and evenly as possible across the sites.

The Safer Bars Training Manual (Graham, 2000b) formed the basis for the extensive training manual developed for this study and covered topics such as legal and safety issues, guidelines for observing in the public space, observational schedule, procedures for recording observations and general rules. A pilot observation session with all observers was conducted at a nearby site comprising numerous licensed premises, restaurants and a cinema complex. 


\section{Observation Procedures}

The development of observational procedures primarily focused on ensuring that the observations were conducted unobtrusively and consistently. They were advised to try to act, behave and dress like they would normally when going out for a "night on the town". Friendly interaction between observers was encouraged to ensure the unobtrusiveness and inconspicuousness of the observations, but they were advised to not discuss how they intended to rate the site or incidents.

Observers were not permitted to carry any obvious recording equipment or writing material. Some used mobile phones to record specific measurements, details or to take notes.

For safety and to allow for inter-rater reliability checks, all observations were completed in pairs. The observer pairs were required to stay together throughout the observational period and travel to and from the observational site from the meeting point. Observers relocated on only one occasion as a result of feeling threatened. There were no occurrences of the observers having to reveal their true purpose to pedestrians, patrons, security staff or Police.

\section{Schedule of Visits}

96 hours of observations carried out. Each site was visited 4 times on both Friday and Saturday night over a four-week period, with each visit being two hours in duration (2200-0000 hours, 0000-0200 hours, 0200-0400 hours and 0400-0600 hours). The order of these shifts was randomly determined at the start of the study, 
and observer pairs and sites were randomly assigned on a weekly basis to control and detect inter-rater reliability issues. At the completion of the observation period, all pairs met back and were given the observation instrument to complete separately (i.e. observers completed the survey without conferring with their partner).

\section{Observational Instrument}

The instrument was heavily based on the survey instrument developed by Ross Homel and colleagues, documented in a series of studies (Homel et al., 1992; Homel and Clark, 1994; Homel et al., 1997; Macintyre and Homel, 1997) focusing on violence and alcohol in licensed venues, which itself has been informed by the pioneering work of Kathryn Graham and colleagues (Graham et al., 1980; Graham and Wells, 2001; Graham et al., 2006). We adapted the instrument to reflect the unit of analysis and our research goals. The major changes were the introduction of queue measures, including length, speed and orderliness (did it snake across the footpath?), and pedestrian flow (volume and speed).

Crowding and low-level aggression (detailed below) were measured by observers locating themselves at a point within the site. Exact locations varied each night, however, observers were given a rough location on a map of the site of where to stand and were advised to stand as close as possible to the most crowded point of the site. Observers were provided hand held counters to keep track of these two variables. All other variables were recorded by observers located at a vantage point opposite the observational site that offered a clear view, provided cover from 
the weather and ensured their safety and unobtrusiveness.

Measurements of crowding, low-level aggression, queues and pedestrian flow were made in the first and last 30 minutes of the visit, partly to observe changes within a visit but also to avoid relying on single measures of key variables.

\section{Measures of Aggression and Crowding}

The measures developed by Macintyre and Homel (1997) were used to capture aggression and crowding:

- crowding the number of low-level contacts with no clear intention to cause harm or act aggressively (e.g. persons brushing past each other, very slight contact and unintended contacts);

- low-level aggression the number of substantial contacts where an intention to act aggressively or to cause harm was probably present at some point in the interaction (e.g. bumps, knocks, spilled drinks, knocked bags and heated arguments); and

- high-level aggression the number of very substantial contacts where an intention to act aggressively or to cause harm was definitely present during the interaction (e.g. pushing, shoving, hitting and fighting).

The distinction between each is that crowding excludes incidents or contacts where there is intent to harm or act aggressively. Contacts of this nature were classified as either low-level aggression or high-level aggression according to 
severity. During training and listed in the training manual for reference, observers were provided with a list of the types of behaviour that should be documented as aggression. Unlike the other two measurements, high-level aggression was measured over the whole two-hour period due to the lower prevalence of such contacts. Observers were also requested to provide details of incidents involving high-level aggression in the observer narrative.

\section{Measures of the Physical and Social Environment}

The physical environment was measured through ratings of several aspects, based primarily on measures from previous studies. Observers completed ratings of the level of lighting, smoking level, cleanliness, upkeep, amount of graffiti and signage and awareness of CCTV surveillance on 10-point scales. The ratings were recoded so that a low score (1) reflected a positive rating (e.g. excellent level of lighting) and a high score (10) a negative rating (e.g. terrible level of lighting) of the physical environment.

The social environment was also measured through ratings of social behaviours that have been shown to be important in the analysis of alcohol-related violence. These include the level of noise from music and voices, sexual activity, contact and competition and permissiveness and standard setting. Observers also rated separately for males and females the amount and severity of the following: hostility, roughness and bumping, rowdiness, swearing and intoxication. Again, these were recorded on a 10-point scale. 


\section{Measures of the Street Population and Queues}

The street population measures rate several important elements of the street environment, including density, flow (the time taken to walk the entire length of the site), demographics (age ratio, gender ratio, size of groups and ethnicity) of each site were recorded.

Queue measures involved recording the number, length and flow (time taken for a patron to enter a queue until they exit the queue, either as a result of being granted entry to the licensed premise, denied entry or their choice of transport arriving) of each queue formed. Types of queues included were those associated with licensed venues, taxis, buses, train, food outlets and ATMs. The orientation of each queue, in terms of alignment along the footpath, was also rated on a five-point scale.

\section{Data checking, cleaning and validation}

Inter-rater reliability checks were performed using correlations based on Pearson's $r$ for those variables that were measured on ten-point scale (i.e. the measures of the physical and social environment). Reliability between the two observers was high for the majority of variables. Visual inspection of the data revealed differences of four or greater (on a 10 point scale) between observers were responsible for the weak correlations ${ }^{\text {iii }}$. Differences could not be linked to individual observers. Various methods of reducing the impact of such variations through recoding into smaller scales did not produce stronger correlations, so these variables (smoking, surveillance, swearing, female intoxication and 
permissiveness) were omitted from further analysis.

The small sample size ( $N=48 ; 6$ sites by 4 visits by 2 nights) could not support analysis incorporating each physical and social environment variable, so aggregate variables were created. Analysis showed the physical environment variables measuring cleanliness, upkeep and graffiti were strongly correlated with each other. An aggregate physical environment variable was created using their average. With respect to the social environment, significant correlations were found between the gendered measures of variables measuring hostility, roughness and rowdiness. Again, An aggregate social environment variable was created using their average. The reliability of each scale was assessed using Cronbach's alpha, with scores of .79 (physical) and .88 (social).

Table 2 contains descriptive statistics for the variables used in the regression analysis presented later. The distributions for low- and high-level aggression, physical environment and crowding were all positively skewed. Social environment, male intoxication and street density were close to normally distributed.

<insert Table 2 about here>

\section{Analytic strategy}

To answer the first research question (what causes crowding) we examined the nature and variety of pedestrian vectors at each site. Observers were tasked to 
draw maps of the sites comprising the major pedestrian paths, queues and obstacles for each visit. Compared to the other elements of the survey instrument, the maps were not recorded systematically by all observers. Complete information for each visit was recorded only for Sites 1 and 6, forcing us to restrict our attention to only these two sites ${ }^{\mathrm{iv}}$. The narrative descriptions for both sites were then examined for qualitative insight. In addition, a new variable was created capturing the amount of cumulative time spent in queues for each site.

Regression modeling was used to answer the second research question (does excessive crowding lead to higher aggression). The strategy for model development was similar to that of Macintyre and Homel (1997): the initial model included a set of control variables representing the major environmental factors that have been demonstrated in observational studies to predict aggression. These were the ratings of the physical environment, the social environment, male intoxication and street density. The second model added the crowding variables (a linear and quadratic term) in order to make comparisons between the first and second model for changes in the control variables. This modeling approach estimates the unique contribution crowding makes to aggression over and above the influence of the control variables. Given the dependent variable was a variable of count data (total observed aggression), a negative binomial model was estimated. All analyses were performed in the statistical programming language $\mathrm{R}$ (R Development Core Team, 2010). 


\section{Results}

\section{Research Question 1: What causes crowding?}

The line frequently inhibited pedestrian flow with many people stepping out onto busy st to pass que (sic). (Observer 8 on Site 3)

Sites 1 and 6 were the only sites with full pedestrian vector information recorded for all time periods. Site 1 comprises two popular nightclubs (each having sizable queues on busy nights) and a night bus stop. Site 6 contains the main taxi rank (marshaled) for the entertainment precinct and an ATM (which very rarely had a queue). The main pedestrian vectors for Sites 1 and 6 are displayed in Figure 2. During different times observers recorded increasingly complex vector diagrams displaying more cross paths. For instance, across most sites jaywalking was more prevalent in later visits as patrons left venues for transport home. Site 1 has clearly more cross flows than Site 6 and based on prior research more crowding incidents are expected to be observed in Site 1 compared to Site 6, all things being equal.

\section{<insert Figure 2 about here>}

Descriptive statistics for Sites 1 and 6 were examined and their distributions are displayed in Figure 3. The two sites are indistinguishable in terms of levels of intoxication and street population, leading us to be confident in assuming that both sites attract similar individuals and the supply of offenders and victims of 
aggression would be comparable in both sites. This may seem surprising given that Site 6 has no licensed premises, but the taxi rank serves the entire entertainment precinct and the majority of patrons leaving the area use the taxi rank to return home. Although the median crowding values are very similar, Site 1 has a longer tail than Site 6, consistent with more complex pedestrian vectors observed in Figure 2. The amount of time spent in queues is also much greater in Site 1 than 6.

<insert Figure 3 about here>

The observer narratives provide insights into important differences between the sites in terms of place management. The venue queues in Site 1 are depicted as disorderly and unmanaged. Security staff actively monitored entry and exit points, but rarely the queue itself. During peak times the queues can be very long, restricting passing foot traffic. The following excerpt features a number of potential problems:

When the line for [nightclub name] started to get busy, patrons started to act hostile after waiting for 15-30 mins for entry. Pathway was blocked by que (sic), there was no security supervision of large que (sic), mostly males intoxicated. Aggression and shoving started in the line, security did not pay attention or monitor. (Observer 4 on Site 1)

Narratives of Sites 1-4 all mention pedestrian bottlenecks in at least one visit, forcing passersby to walk on the road. Long waiting times, coupled with a lack of 
place management, serve as precipitating factors of criminal motivation. The circumstances where this spills over into aggressive behavior are far from established, although the disinhibiting influence of alcohol seems to be a good candidate explanation. Other narratives describe smoking and drinking in queues not challenged by staff, a form of expectation setting originating in poor place management. In contrast, Site 6 had quite effective place management:

Taxi marshals were very much in control of queue (did not tolerate queue cutting). (Observer 10 on Site 6)

This is not surprising given the taxi rank was managed by dedicated marshals. The ineffective management in Site 1 is probably a product of competing and overstretched resources rather than intended incompetence. It is easy to imagine that venue queues are neglected during peak times.

The preceding analysis established that in terms of street population and temperament Sites 1 and 6 are very similar. However, they differ with respect to the potential for aggression. More complex pedestrian vectors in Site 1 correlate with more crowding incidents. The differences in place management styles and capacity led to greater waiting times in Site 1. Figure 4 shows the observed aggression for both sites by time of night.

<insert Figure 4 about here>

Site 1 hosted substantially more aggression across the night than Site 6, apart from 
the 2200- 2400 hours visit, where the level was approximately equal. Given the amount of time spent in queue, the higher volume of crowding, the more complex pedestrian flows and the different queue management styles, it is not surprising that higher levels of aggression were observed in Site 1. In addition, changes in aggression levels match changes in the complexity of pedestrian cross paths across the night.

\section{Research Question 2: Does excessive crowding directly lead to increased} aggression?

In 96 hours of observations a total of 136 acts of aggression were observed, of these $42(30.88 \%)$ were considered high-level. Compared to observational studies inside premises, this level is exceptionally high; rates of aggression per 100 hours of observation for various studies were 34 (Homel and Clark, 1994); 25.2 (Graham et al., 1980); 10.7 (Homel et al., 1992). Forsyth et al. (2005) reported more aggression outside premises than inside. Consistent with much of the literature, differences in aggression were observed between sites and by time of night.

The results of the negative binomial models are displayed in Table 3. Model 1 features the control variables related to aggression established in extant literature. There are statistically significant relationships for the social environment, but not for male intoxication, physical environment or street density. Graham and Homel (2008) note that the social environment usually has a stronger influence than the physical environment, so the results here are consistent with the literature. 
<insert Table 3 about here>

Model 2 adds the linear and quadratic crowding terms, both statistically significant (exact $p=0.073$ and 0.025 respectively).

The interpretation of crowding is more complicated because of the quadratic term. The linear term determines the overall relationship and is positive in these dataaggression initially increases with increased crowding. The quadratic term influences how quickly this relationship changes and in what direction. A negative quadratic term, as observed here, acts to slow down positive relationships and in some circumstances reverses the sign of the relationship. The ratio of linear to quadratic coefficients indicates the point at which the negative quadratic relationship cancels out the initial positive linear tendency and the curve turns downwards. For these data, the point at which increased crowding no longer leads to increased aggression is $0.9\left(=\frac{0.59}{-2 *-0.33}\right)$ standard deviations. Of the 48 visits, only 8 had crowding values greater than this threshold.

Figure 5 illustrates the impact of crowding on expected counts of aggression, all things being equal. Predicted counts of aggression were determined by using the estimated regression equation from Model 2. Two scenarios are presented. In the first all control variables are held fixed at their mean values and a range of crowding values are used to compute expected aggression counts. The expected difference between a site with low crowding (two standard deviations below the mean) and average crowding is about three incidents of aggression, all things being equal (the maximum count for aggression in a single visit was 13). The 
second scenario is the same as the first but the social environment variable-the most powerful of the control variables-has a fixed value of one standard deviation above the mean. The difference between low and average crowding is about five incidents of aggression. The difference between the two scenarios is akin to comparing two sites that are identical except with respect to the social environment.

\section{<insert Figure 5 about here>}

The only meaningful change to the control variables in Model 2 is that male intoxication displays a significant relationship once the influence of crowding is partialled out. While the coefficient for the street density variable is higher compared to the estimate in Model 1, it is not statistically significant.

Examining the diagnostic statistics for each model reveals the AIC (Akaike Information Criterion), signifying the goodness of fit, is practically identical across each model. The BIC (Bayesian Information Criterion), which penalises the loss of degrees of freedom to a greater extent than the AIC, increases as the models become more complex. Residual plots were generated for both models and patterns indicating problems in model fit were sought. The residual distributions were practically identical, with Model 2 displaying a slightly tighter distribution.

\section{Discussion}


This study measured aggression and major environmental correlates in the public space of a popular entertainment precinct, something that, to our knowledge, has not been conducted using a systematic observational methodology to date. We sought to answer two research questions: (i) what causes crowding? and (ii) does excessive crowding directly lead to increased aggression?

To answer the first research question two sites were compared in terms of street density, levels predicted counts of aggression of male intoxication, pedestrian vectors, crowding, waiting times and aggression. The site with the consistently highest aggression displayed pedestrian vectors with more cross paths, higher levels of crowding, more time spent waiting in queues and ineffective queue management practices. No differences were observed in the number of patrons in each site nor intoxication levels.

In terms of the second research question, crowding was shown to have an impact on the frequency of aggression even after controlling for major explanatory variables. The social environment and male intoxication had significant relationships to frequency of aggression, as expected, but not for the physical environment and street density. These results show that aggression is more than just the product of the number of people on the street and how much they drink.

A finding of interest but not the focus of the study was much higher rates of aggression were observed than previous studies conducted inside premises. There are three plausible explanations for this finding: (a) the ratio of aggression occurring outside to inside has always been this disparate and this study is simply 
the first to quantify it; (b) over time there has been a displacement of aggression from inside to outside premises; and (c) there are now higher rates of aggression compared to historic levels. Regardless which is the best explanation, the extent of violence observed in public spaces in an entertainment precinct suggests that further researcher interest is warranted.

There are a number of weaknesses in this study. First, the study was conducted in June-July 2010, during the university holidays. This was mid-winter and the number of patrons entering the study region was probably lower than in warmer months ${ }^{\mathrm{v}}$. Also, had the study taken place in the summer months the observed relationships may be different (waiting times in winter may be a precipitator but not in summer). Second, the low sample size limits the extent to which inferences can be drawn. But the fact that significant relationships were observed with a small data set, and nearly all in line with theory and past research, suggest the relationships are fairly easy to detect. The level of aggression compared to previous studies is indicative of this. Third, as each visit was conducted on a different day the observed temporal profile may not reflect a typical night in this entertainment precinct. Last, the study is by nature correlational so there is a limit to the inferences that can be drawn from these data.

The findings have a number of prevention implications, albeit tentative given the scope of the study. First, effective queue management has the potential for reducing aggression. Situational precipitators appear to operate in queues, most notably where formal management is absent, queues are slow or queue jumping is common. Removing or alleviating these factors will, therefore, reduce the 
potential for violence. A policy of proactive queue management would be advantageous for licensees and security staff as it provides additional opportunities for screening patrons prior to entry and detecting intoxicated or troublesome individuals. In addition, queue management is likely to be of interest to local Liquor Accords, entities that have renewed relevance in the context of entertainment precincts.

The second area of prevention is the design of public spaces. Places vulnerable to crowding need to be redesigned in order to make movement easier and to prevent congestion and pedestrian crossflows. This study has demonstrated that certain places are prone to crowding, but much more work needs to be carried out to understand the relationship between physical design and crowding. Designers need to incorporate the principles of Crime Prevention Through Environmental Design as well as have a detailed understanding of how humans move and navigate themselves in entertainment precincts.

While strongly tied to the local context of the study site, the implications of this study extend further to the night-time economies of other countries. A comparison of international NTE regulatory and planning models identified precinct management, including crowding and queuing, as a key issue for many NTEs throughout Canada, USA, United Kingdom and Europe (Hae, 2011; Madenson and Knuttson, 2011; Talbot, 2006; 2009). Some strategies have been enacted in response to these issues in other countries, such as a 'no queue after 1am' policy (Matthews, 2009). The results of this study could inform new or enhanced strategies in these NTEs, or provide a basis and direction for the further exploration of the issues. 
In terms of future research, there is considerable scope to enhance this study. We found considerable variation in aggression, crowding and management practices across space and time. For instance, narrative accounts imply contrasting management practices from one nightclub on different nights; staff were highly effective and worked well to diffuse situations on one night, yet on others were responsible for the worst behaviour across the sites. The following accounts describe the same site on different Saturday nights:

A fight broke out inside [nightclub 1] and fighters were evicted and separated. One was taken away in paddywagon [police vehicle]. Lines were disorderly and non (sic) one was monitoring the queues, only entry/exits. As result, numerous (5) separate (sic) incidents of high level aggression broke out in [nightclub 1] queue. Police were only there to break first fight up as they were still dealing with evicted man who got taken away. Fights were also large and mainly males as disorder of queue attracted more people. One of the high level incidents was from people who kept trying to fight after being kicked out. Also ppl (sic) were highly intoxicated and kept jumping out in front of cabs. Bus queue was also disorganised, however everyone waiting seemed quite placid. Also security for [nightclub 1] were not obvious/noticeable as dressed in black suits, similar to patrons. (Observer 10 on Site 1)

Saw no aggression. [nightclub 1] at end of night guy was asked to leave queue he said something lack to bouncer, bouncer ended up just walking 
away. [nightclub 2] line was about $3 \mathrm{X}$ as long at end but took about the same amount of time to get in. [nightclub 2]'s bouncers watched line and got people to straighten up and move up. (Observer 7 on Site 1)

Whether this is a function of different staff, managers, patrons or an interaction of these and other factors is beyond the scope of this study. But in the presence of such variation, studies need to be designed with this in mind. A much larger sample size is required to fully account for the relationships explored here. A stronger focus on queueing and crowding would allow greater insight into the dynamics of each. The knowledge established in this study is basic-crowding makes aggression more likely-but what designers need to know is under what circumstances does crowding occur and how can these factors be made less likely or frequent. Queueing outside licensed premises and around transport nodes seems an area ripe for further work, particularly in pragmatic ways that queue management practices can nullify the types of precipitating effects that waiting to enter a nightclub or for transport appear to trigger.

\footnotetext{
${ }^{\mathrm{i}}$ In the following discussion individual studies are not cited for each finding, due to space restrictions. The authors can provide this for interested readers or consult Graham and Homel (2008).

ii One hour of observation outside for every three hours inside premises.

iii Graham et al. (2006) used a discrepancy threshold of two on a 10 point scale.

iv The observed results for the other four sites were consistent with the results reported here, albeit the missing values.

${ }^{v}$ Overnight temperatures in Brisbane during winter average 11 degrees Celsius. While this will strike some readers as relatively mild, there is an observable difference in patronage between summer and winter periods.
} 


\section{References}

Block, R. L. and Block, C. R. (1995). Space, Place and Crime: Hot Spot Areas and Hot Places of Liquor-Related Crime. In Eck, J. E. and Weisburd, D. L., editors, Crime and Place, volume 4 of Crime Prevention Series, pages 145-183. Criminal Justice Press, Monsey, NY.

Brantingham, P. J. and Brantingham, P. L. (2008). Crime Pattern Theory. In Wortley, R. and Mazerolle, L., editors, Environmental Criminology and Crime Analysis, pages 78-93. Willan Publishing, Cullompton.

Brisbane City Council (2010). About the Valley Special Entertainment Precinct. http://www.brisbane.qld.gov.au/planning-building/local-plans/inner-city/valley-specialentertainment-precinct/about-the-valley-sep/index.htm [Last Accessed: 6 July, 2011].

Briscoe, S. and Donnelly, N. (2001). Temporal and Regional Aspects of Alcohol-Related Violence and Disorder. Alcohol Studies Bulletins 1, Bureau of Crime Statistics and Research New South Wales, Sydney.

Burke, M. and Schmidt, A. (2009). The Death and Life of Great Australian Music: Planning for Live Music Venues in Australian Cities. In Proceedings of 4th National Conference on the State of Australian Cities. URI http://www. promaco. com. au/2009/soac/. Burrell, A. and Erol, R. (2006). Violence in the Night-Time Economy: Tracking Hot Spots over Time. Technical report, UCL Jill Dando Institute of Crime Science, London, UK. Cameron, A. (2005). Microeconometrics: Methods and Applications. Cambridge University Press, Cambridge.

Cameron, A. and Trivedi, P. (1998). Regression Analysis of Count Data. Cambridge University Press, Cambridge.

Chikritzhs, T., Dietze, P., Allsop, S., Daube, M., Hall, W., and Kypri, K. (2009). The "Alcopops" Tax: Heading in the Right Direction. Medical Journal of Australia, 190:294-5. Cohen, L. E. and Felson, M. (1979). Social Change and Crime Rate Trends: A Routine Activity Approach. American Sociological Review, 44(4):588-608. Collins, D. and Lapsley, H. (2008). The Costs of Tobacco, Alcohol and Illicit Drug Abuse to Australian Society in 2004/05. Department of Health and Ageing, Canberra. Cornish, D. B. and Clarke, R. V. (2008). The Rational Choice Perspective. In Wortley, R. and Mazerolle, L., editors, Environmental Criminology and Crime Analysis, pages 21-47. Willan Publishing, Cullompton.

Cornish, D. B. and Clarke, R. V. G. (1986). The Reasoning Criminal: Rational Choice Perspectives on Offending. Springer-Verlag, New York.

Cozens, P. and Grieve, S. (2009). Designing Crime Precipitators in Northbridge After

Dark: Urban Governance in Slumber. In City Growth, Sustainability, Vitality and

Vulnerability, Perth. Australian Sustainable Cities Network.

Donkin, S. and Birks, D. (2007). Victims and Offenders of Night-Time Economy

Violence. Technical report, UCL Jill Dando Institute of Crime Science, London, UK. Douglas, M. (1998). Restriction of the Hours of Sale of Alcohol in a Small Community:

A Beneficial Impact. Australian and New Zealand Journal of Public Health, 22(6):714-719.

Eck, J. E. (1994). Drug Markets and Drug Places : A Case-Control Study of the Spatial

Structure of Illicit Drug Dealing. Unpublished doctoral thesis, University of Maryland at College Park.

Fitzgerald, J., Mason, A., and Borzycki, C. (2010). The Nature of Assaults Recorded on

Licensed Premises. Bureau Brief 43, NSW Bureau of Crime Statistics and Research, Sydney. Forsyth, A. (2006). Assessing the Relationships Between Late Night Drinks Marketing

and Alcohol- Related Disorder in Public Space. Glasgow: Alcohol Education Research

Council (AERC).

Forsyth, A., Cloonan, M., and Barr, J. (2005). Factors Associated with Alcohol-Related

Problems within Licensed Premises. Glasgow: NHS Board.

Graham, K. (2000a). Preventive Interventions for On-Premise Drinking: A Promising but

Underresearched Area of Prevention. Contemp. Drug Probs., 27:593.

Graham, K. (2000b). Safer Bars Training Manual.

http://publish.uwo.ca/ kgraham/safer_bars.html [Last Accessed June 30, 2010].

Graham, K., Bernards, S., Osgood, D. W., and Wells, S. (2006). Bad Nights or Bad Bars?

Multi- Level Analysis of Environmental Predictors of Aggression in Late-Night Large- 
Capacity Bars and Clubs. Addiction, 101(11):1569.

Graham, K. and Homel, R. (2008). Raising the Bar: Preventing Aggression in and around

Bars, Clubs and Pubs. Willan Publishing, Cullompton.

Graham, K., La Rocque, L., Yetman, R., Ross, T., and Guistra, E. (1980). Aggression and

Barroom Environments. Journal of Studies on Alcohol, 41(3):277-292.

Graham, K., Osgood, D., Zibrowski, E., Purcell, J., Gliksman, L., Leonard, K., Pernanen,

K., Saltz, R., and Toomey, T. (2004). The Effect of the Safer Bars Programme on Physical

Aggression in Bars: Results of a Randomized Controlled Trial. Drug and Alcohol Review,

23(1):31-41.

Graham, K. and Wells, S. (2001). Aggression among Young Adults in the Social Context

of the Bar. Addiction Research, 9(3):193-219.

Graham, K., West, P., and Wells, S. (2000). Evaluating Theories of Alcohol-Related

Aggression Using Observations of Young Adults in Bars. Addiction, 95(6):847-863.

Hadfield, P. (2006). Bar Wars: Contesting the Night in Contemporary British Cities.

Oxford University Press, USA.

Hadfield, P. and Measham, F. (2011). Lost orders? Alcohol and Law Enforcement in

England and Wales: Final report to the Portman Group. The Portman Group.

Hae, L. (2011). Gentrification and Politicization of Nightlife in New York City. ACME:

An International E-Journal for Critical Geographies, 11(3):564-584.

Hobbs, D., Hadfield, P., Lister, S., and Winlow, S. (2003). Bouncers: Violence and

Governance in the Night-Time Economy. Oxford University Press, New York.

Homel, R. and Clark, J. (1994). The Prediction and Prevention of Violence in Pubs and

Clubs. In Clarke, R. V. G., editor, Crime Prevention Studies, volume 3, chapter 1, pages 1-46.

Criminal Justice Press, Monsey, NY.

Homel, R., Hauritz, M., McIlwain, G., Wortley, R., and Carvolth, R. (1997). Preventing

Drunkenness and Violence around Nightclubs in a Tourist Resort. In Clarke, R. V., editor,

Situational Crime Prevention: Successful Case Studies, pages 263-282. Criminal Justice Press,

Monsey, NY, 2nd edition.

Homel, R., Tomsen, S., and Thommeny, J. (1992). Public Drinking and Violence: Not

Just an Alcohol Problem. Journal of Drug Issues, 22:679-697.

Jeffs, B. and Saunders, W. (1983). Minimizing Alcohol Related Offences by

Enforcement of the Existing Licensing Legislation. British Journal of Addiction, 78:67-77. Jochelson, R. (1997). Crime and Place: An Analysis of Assaults and Robberies in Inner

Sydney. NSW Bureau of Crime Statistics and Research, Sydney.

Kypri, K., Jones, C., McElduff, P., and Barker, D. (2011). Effects of Restricting Pub

Closing Times on Night-Time Assaults in an Australian City. Addiction, 106(2):303-310.

Laslett, A., Catalano, P., Chikritzhs, T., Dale, C., Doran, C., Ferris, J., Jainullabudeen, T.,

Livingston, M., Matthews, S., Mugavin, J., et al. (2010). The Range and Magnitude of Alcohol's Harm

to Others. AER Centre for Alcohol Policy Research, Turning Point Alcohol and Drug Centre, Eastern

Health, Fitzroy, Victoria.

Law, Justice and Safety Committee (2010). Inquiry into Alcohol-Related Violence.

Number 74. Legislative Assembly of Queensland, Queensland.

Lesjak, M., McMahon, G., and Zanette, L. (2008). Alcohol Harm and Cost at a

Community Level: Data from Police and Health. Rural Remote Health, 8(2):878.

Livingston, M. (2008). Alcohol outlet density and assault: A spatial analysis. Addiction,

103(4), 619-628.

Macintyre, S. and Homel, R. (1997). Danger on the Dance Floor: A Study of Interior

Design, Crowding and Aggression in Nightclubs. Policing for prevention: Reducing crime,

public intoxication, and injury. Crime Prevention Studies, 7:91-114.

Madensen, T. and Eck, J. (2008). Violence in Bars: Exploring the Impact of Place

Manager Decision-Making. Crime Prevention \& Community Safety, 10(2):111-125.

Madensen, T. and Knutsson, J., editors (2011). Preventing Crowd Violence, volume 26 of

Crime Prevention Series. Lynne Rienner Publishers, Boulder, CO.

Matthews, S. (2009). To Compare Regulatory And Planning Models Which Reduce

Crime In The Night Time Economy. Final Report to the Winston Churchill Memorial Trust of

Australia.

Moore, S., Brennan, I., and Murphy, S. (2011). Predicting and Measuring Premises-Level

Harm in the Night-Time Economy. Alcohol and Alcoholism, 46(3):357-363.

Moore, S., Flajslik, M., Rosin, P., and Marshall, D. (2008). A Particle Model of Crowd

Behavior: Exploring the Relationship between Alcohol, Crowd Dynamics and Violence. 
Aggression and Violent Behavior, 13(6):413-422.

Morgan, A. and McAtamney, A. (2009). Key Issues in Alcohol-Related Violence.

Summary Paper 4, Australian Institute of Criminology, Canberra.

Murray, D. (2011). Violence in Paradise: The Physical, Social and Perceived

Environments in a Beachside Entertainment District. PhD thesis, School of Criminology and

Criminal Justice, Griffith University, Brisbane, Australia.

National Competition Council (2004). Assessment of governments' progress in implementing the

National Competition Policy and related reforms: Volume one: Assessment. Melbourne: National

Competition Council (http://ncp.ncc.gov.au/docs/2004\%20assessment.pdf).

Nelson, A. L., Bromley, R. D. F., and Thomas, C. J. (2001). Identifying Micro-Spatial

and Temporal Patterns of Violent Crime and Disorder in the British City Centre. Applied

Geography, 21(3):249-274.

Newton, A., Sarker, S., Pahal, G., Van den Bergh, E., and Young, C. (2007). Impact of

the New Uk Licensing Law on Emergency Hospital Attendances: A Cohort Study. Emergency

Medicine Journal, 24(8):532.

Office of Liquor and Gaming Regulation (2011). DSP Snapshot Fortitude Valley.

http://www.olgr.qld.gov.au/resources/liquorDocs/DSP-snapshot-Fortitude-Valley.pdf [Last

Accessed: 7 July, 2011].

Osgood, D. (2000). Poisson-Based Regression Analysis of Aggregate Crime Rates.

Journal of Quantitative Criminology, 16(1):21-43.

Österberg, E. (2004). Effects of Price and Taxation. In Heather, N. and Stockwell, T., editors, The Essential Handbook of Treatment and Prevention of Alcohol Problems, chapter 12, pages 199-212. John Wiley \& Sons Ltd, Chichester.

Plant, M., Plant, M., and Thornton, C. (2002). People and Places: Some Factors in the Alcohol- Violence Link. Journal of Substance Use, 7(4):207-213.

Pointing, S., Hayes-Jonkers, C., Stone, R., Brinn, D., and Clough, A. (2011). Is it Worth Emergency Departments Recording Information about Alcohol-Related Assault Occurring in Inner- City, Late-Night Entertainment Precincts? Emergency Medicine Australasia, 23(1):106107.

Poynton, S., Donnelly, N., Weatherburn, D., Fulde, G., and Scott, L. (2005). The Role of Alcohol in Injuries Presenting to St Vincent's Hospital Emergency Department and the Associated Short- Term Costs. Alcohol Studies Bulletin 6, AER Foundation.

Queensland Government (2010). Queensland Government Response to Law, Justice and Safety Committee's Final Report into Alcohol-Related Violence. Tabled Paper, 30 August 2010, Queensland Government, Brisbane.

R Development Core Team (2010). R: A Language and Environment for Statistical Computing. R Foundation for Statistical Computing, Vienna, Austria.

Rehm J et al. Global burden of disease and injury and economic cost attributable to alcohol use and alcohol use disorders. Lancet, 2009, 373(9682):2223-2233.

Roncek, D. W. and Maier, P. A. (1991). Bars, Blocks, and Crimes Revisited: Linking the Theory of Routine Activities to the Empiricism of Hot Spots. Criminology, 29(4):725-753.

Stockwell, T. (2001). Responsible Alcohol Service: Lessons from Evaluations of Server Training and Policing Initiatives. Drug and Alcohol Review, 20(3):257-265.

Stockwell, T. and Chikritzhs, T. (2009). Do Relaxed Trading Hours for Bars and Clubs Mean More Relaxed Drinking? A Review of International Research on the Impacts of Changes to Permitted Hours of Drinking. Crime Prevention and Community Safety, 11:153-70.

Talbot, D. (2006). The Licensing Act 2003 And The Problematization Of The NightTime Economy: Planning, Licensing And Subcultural Closure In The UK. International Journal of Urban and Regional Research, 30(1):159-171.

Talbot, D. (2009). Regulating The Other Side: Disorder, Exclusion And Subcultural Closure In The Night-Time Economy. World Leisure Journal, 51(1):14-26. Voas, R., Lange, J., and Johnson, M. (2002). Reducing High-Risk Drinking by Young Americans South of the Border: The Impact of a Partial Ban on Sales of Alcohol. Journal of Studies on Alcohol, 63(3):286-292.

Voas, R., Romano, E., Kelley-Baker, T., and Tippetts, A. (2006). A Partial Ban on Sales to Reduce High-Risk Drinking South of the Border: Seven Years Later. Journal of Studies on Alcohol, 67(5):746-753.

Wagenaar, A., Salois, M., and Komro, K. (2009). Effects of Beverage Alcohol Price and Tax Levels on Drinking: A Meta-Analysis of 1003 Estimates from 112 Studies. Addiction, 104(2):179-190. 
WHO Regional Office for Europe (2009). Evidence for the effectiveness and cost-effectiveness of interventions to reduce alcohol-related harm. Copenhagen: WHO Regional Office for Europe (http://www. euro.who.int/_data/assets/pdf_file/0020/43319/E92823.pdf).

Wiggers, J. (2007). Reducing Alcohol-Related Violence and Improving Community Safety: The Alcohol Linking Program. New South Wales Public Health Bulletin, 18(6):83-85.

Wiggers, J., Jauncey, M., Considine, R., Daly, J., Kingsland, M., Purss, K., Burrows, S., Nicholas, C., and Waites, R. (2004). Strategies and Outcomes in Translating Alcohol Harm Reduction Research into Practice: The Alcohol Linking Program. Drug and Alcohol Review, 23(3):355-364.

Wikstrom, P.-O. H. (1995). Preventing City-Center Street Crimes. In Farrington, D. P. and Tonry, M., editors, Building a Safer Society: Strategic Approaches to Crime Prevention, volume 19 of Crime and Justice: A Review of Research, pages 429-468. University of Chicago Press, Chicago.

Wortley, R. (1997). Reconsidering the Role of Opportunity in Situational Crime Prevention. In Newman, G., Clarke, R., and Shoham, S., editors, The Social Psychology of Crime: Theoretical Foundations, pages 65-82. Ashgate Publishing, Aldershot, United Kingdom.

Wortley, R. (1998). A Two-Stage Model of Situational Crime Prevention. Studies on Crime and Crime Prevention, 7(2):173-188.

Wortley, R. (2001). A Classification of Techniques for Controlling Situational Precipitators of Crime. Security Journal, 14(4):63-82.

Wortley, R. (2008). Situational Precipitators of Crime. In Wortley, R. and Mazerolle, L., editors, Environmental Criminology and Crime Analysis, chapter 3, pages 48-69. Willan Publishing, Cullompton. 
Table 1: List of sites for observational study

\begin{tabular}{|c|c|c|}
\hline Site & Location description & Features \\
\hline 1 & $\begin{array}{l}\text { Warner St, between Wickham St and Ann St } \\
\text { (nightclub and bus stop side) }\end{array}$ & $\begin{array}{l}\text { Two licensed } \\
\text { premises, } \\
\text { NightLink bus stop }\end{array}$ \\
\hline 2 & $\begin{array}{l}\text { Ann St, between Brunswick St and Warner St } \\
\text { (The Beat side) }\end{array}$ & $\begin{array}{l}\text { Two licensed } \\
\text { premises, one with } \\
\text { multiple queues }\end{array}$ \\
\hline 3 & $\begin{array}{l}\text { Brunswick St, between Ann St and McLachlan } \\
\text { St (Empire side) }\end{array}$ & $\begin{array}{l}\text { Three licensed } \\
\text { premises }\end{array}$ \\
\hline 4 & $\begin{array}{l}\text { Ann St, between Brunswick St and Marshall St } \\
\text { (Monastery/Mustang/Cloudland side) }\end{array}$ & $\begin{array}{l}\text { Three licensed } \\
\text { premises }\end{array}$ \\
\hline 5 & $\begin{array}{l}\text { Brunswick St, between Wickham St and } \\
\text { Alfred St (Railway station side) }\end{array}$ & $\begin{array}{l}\text { Entry to railway } \\
\text { station located } \\
\text { within shopping } \\
\text { centre }\end{array}$ \\
\hline 6 & $\begin{array}{l}\text { Wickham St, between Brunswick St and } \\
\text { Warner St (taxi rank side) }\end{array}$ & $\begin{array}{l}\text { NightLink Secure } \\
\text { taxi rank, ATM }\end{array}$ \\
\hline
\end{tabular}


TableTable 2: Descriptive statistics for key observed variables

\begin{tabular}{lrrrr}
\hline & Mean & \multicolumn{1}{c}{ SD } & Min & Max \\
\hline low-level aggression & 1.96 & 2.21 & 0.00 & 8.00 \\
high-level aggression & 0.88 & 1.31 & 0.00 & 5.00 \\
physical environment & 3.60 & 1.24 & 1.67 & 7.33 \\
social environment & 3.75 & 1.29 & 1.42 & 6.33 \\
male intoxication & 6.15 & 1.68 & 2.50 & 9.00 \\
street density & 4.97 & 1.93 & 1.00 & 8.50 \\
crowding & 39.12 & 43.50 & 0.00 & 154.00 \\
\hline
\end{tabular}


Table 3: Model results for total aggression

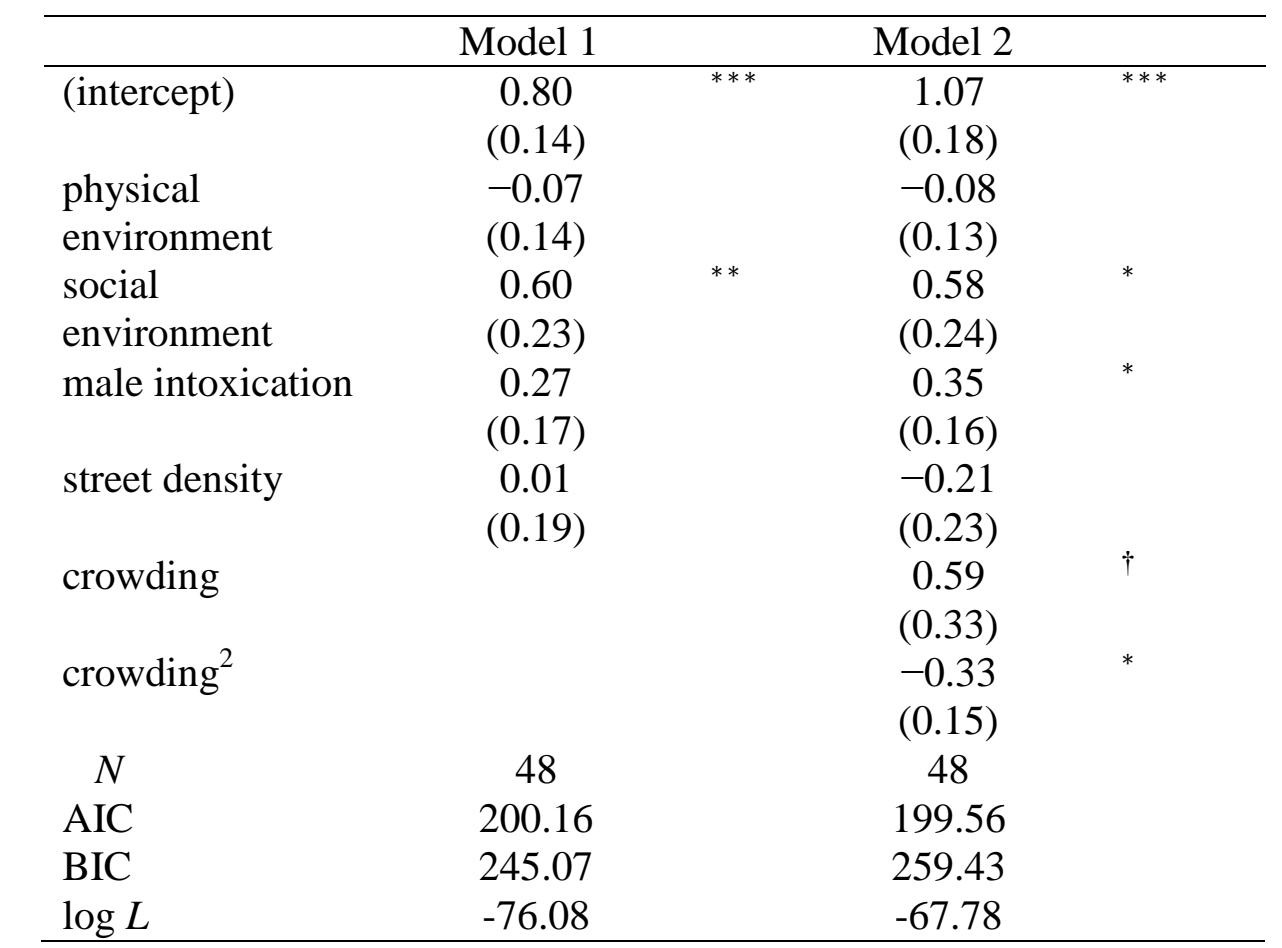

Standard errors in parentheses

${ }^{\dagger}$ significant at $p<.10 ;{ }^{*} p<.05 ;{ }^{* *} p<.01 ;{ }^{* * *} p<.001$ 


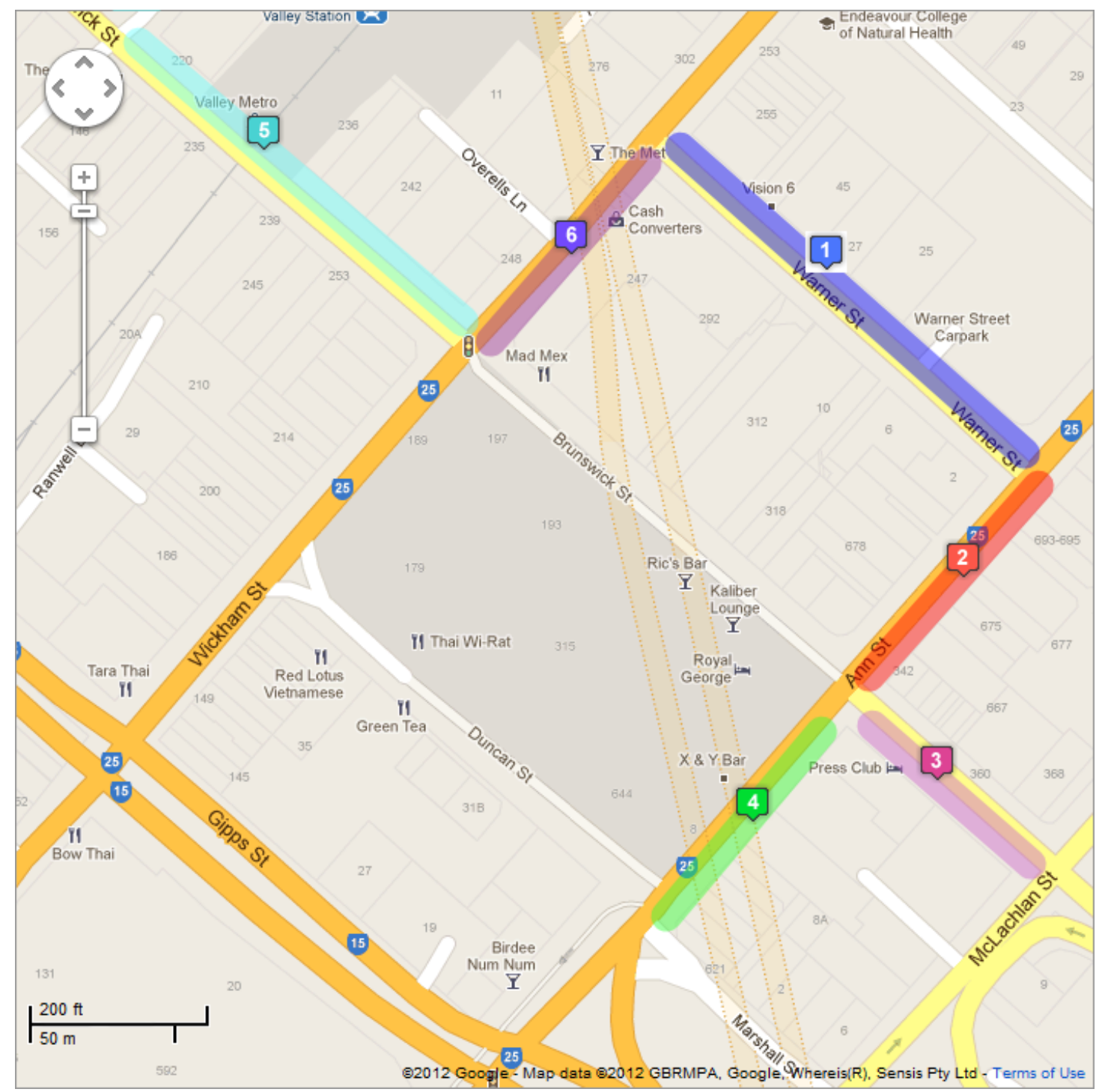

Figure 1: Map of observational sites within Fortitude Valley. 
Site 1

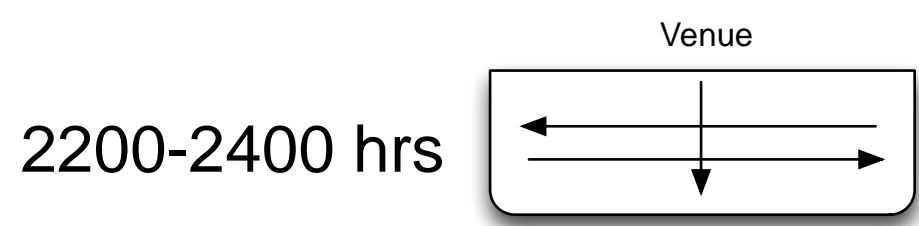

Road

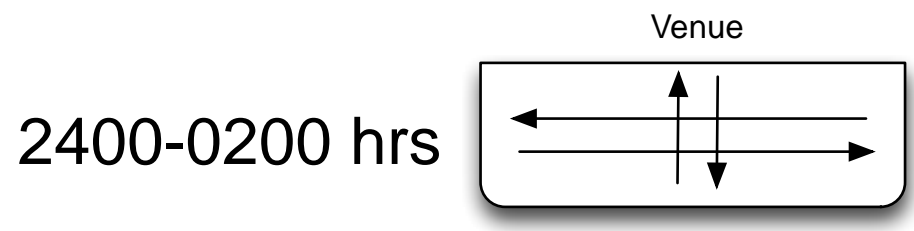

Road

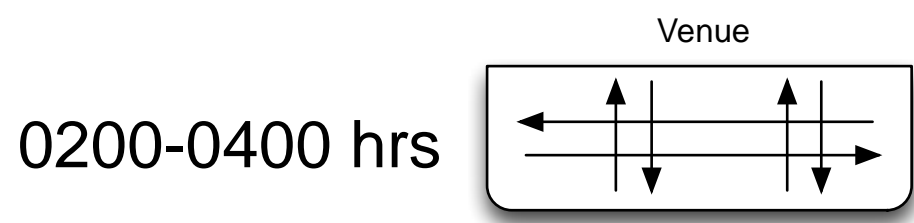

Road

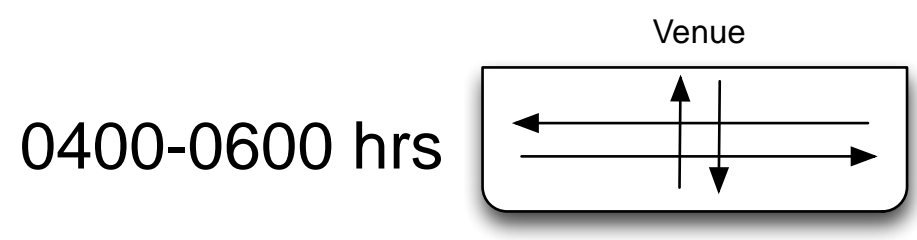

Road
Site 6

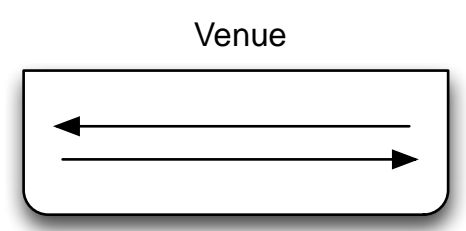

Road

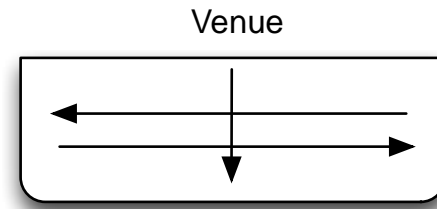

Road

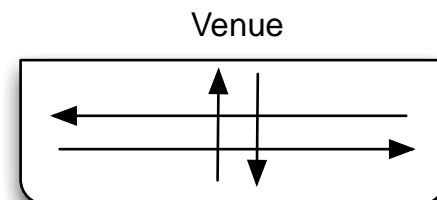

Road

Venue

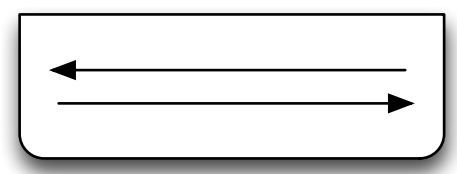

Road

Figure 2: Main Pedestrian Flows by Time of Visit for Sites 1 and 6. 

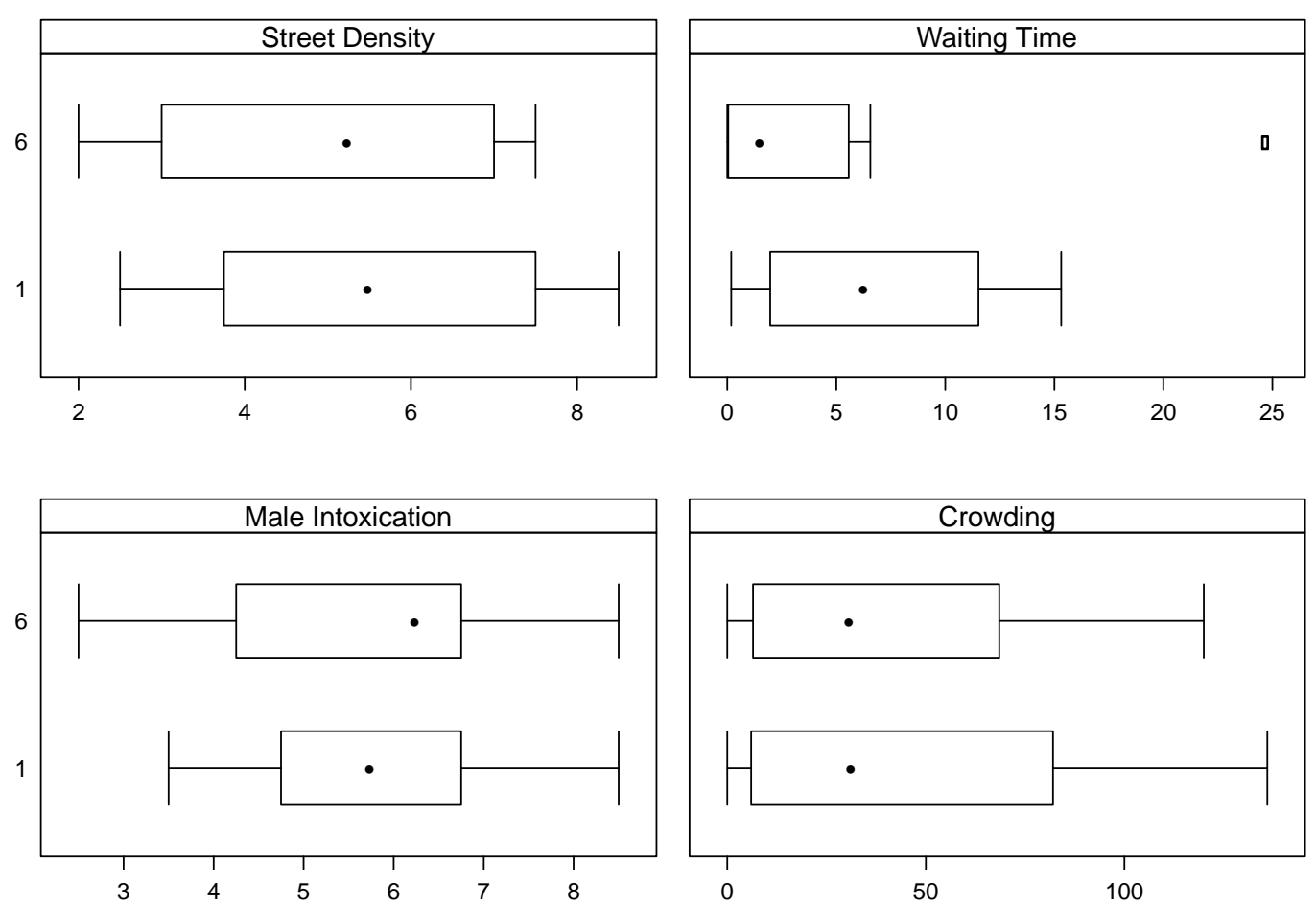

Figure 3: Box and Whisker Plots of Major Explanatory Variables for Sites 1 and 6 


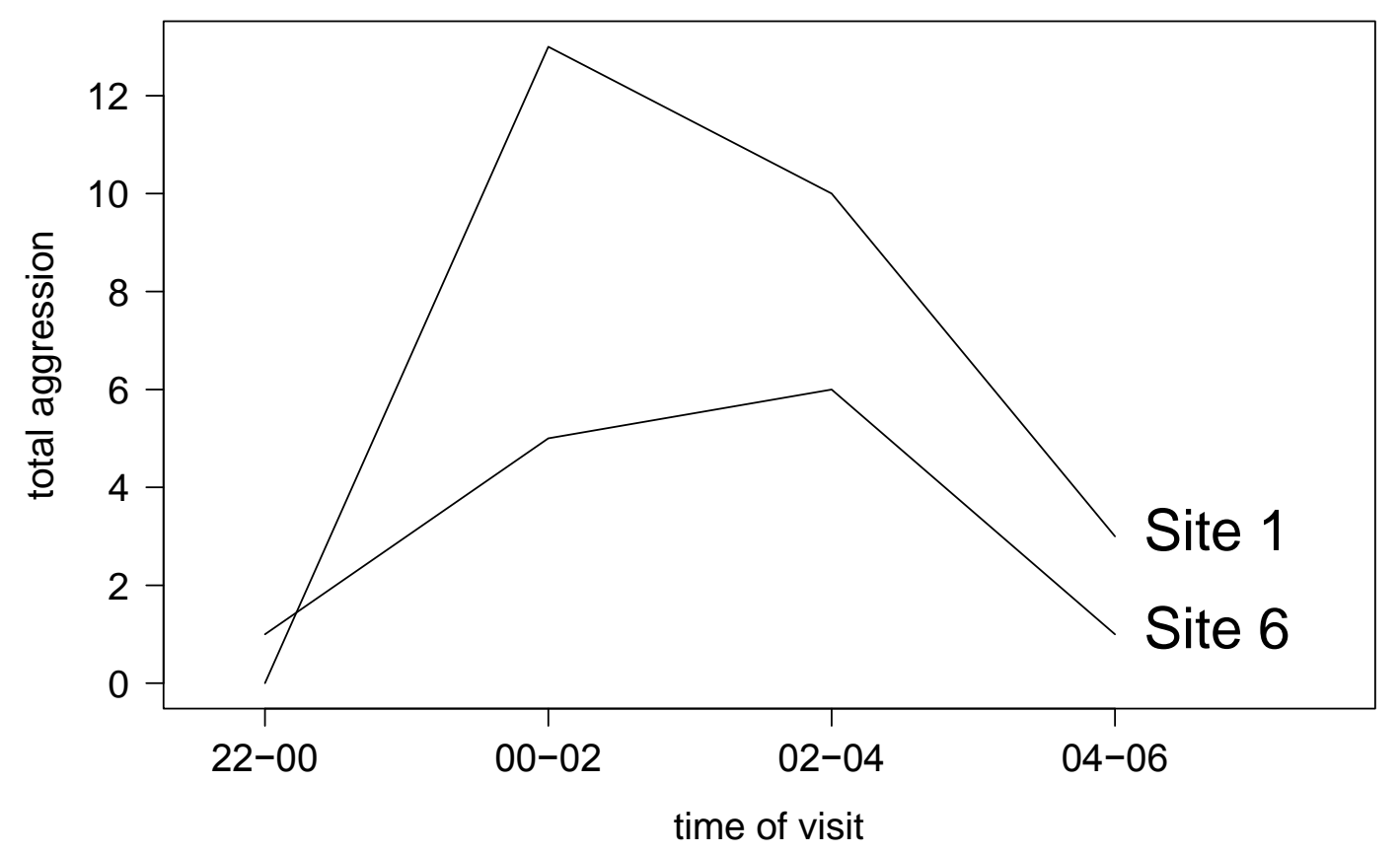

Figure 4: Temporal Patterns in Aggression for Sites 1 and 6 


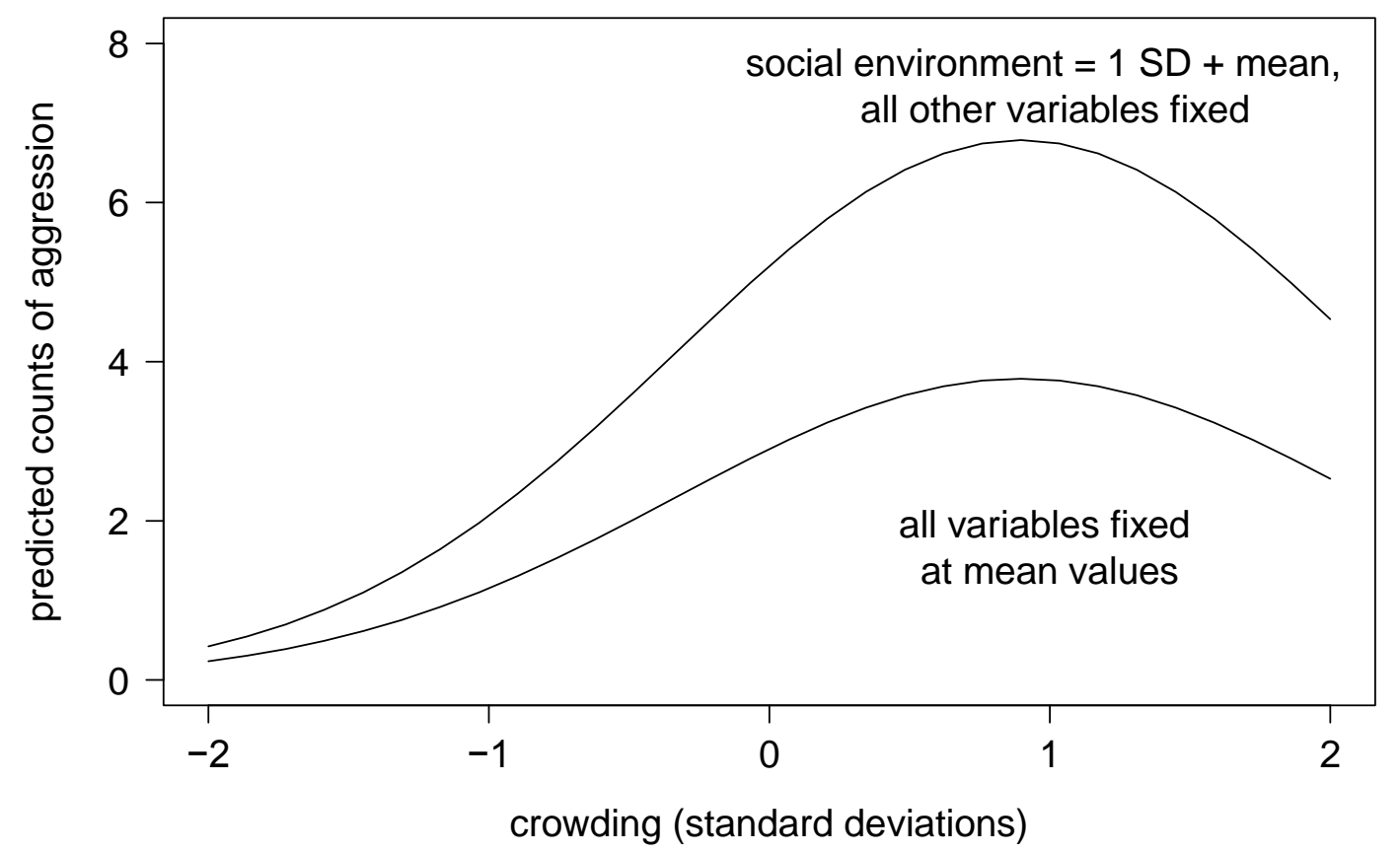

Figure 5: Visualising the Relationship between Crowding and Aggression 